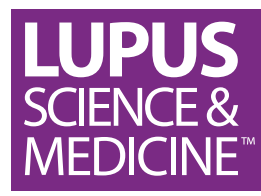

\title{
Lupus patient decisions about clinical trial participation: a qualitative evaluation of perceptions, facilitators and barriers
}

To cite: Arriens C, Aberle T, Carthen F, et al. Lupus patient decisions about clinical trial participation: a qualitative evaluation of perceptions, facilitators and barriers. Lupus Science \& Medicine 2020;7:e000360. doi:10.1136/ lupus-2019-000360

Received 4 September 2019 Revised 18 December 2019 Accepted 5 January 2020
Check for updates

(C) Author(s) (or their employer(s)) 2020. Re-use permitted under CC BY-NC. No commercial re-use. See rights and permissions. Published by BMJ.

\section{${ }^{1}$ Arthritis and Clinical} Immunology, Oklahoma Medical Research Foundation, Oklahoma City, Oklahoma, USA

${ }^{2}$ Internal Medicine, University of Oklahoma Health Sciences Center, Oklahoma City,

Oklahoma, USA

${ }^{3}$ College of Pharmacy, University of Oklahoma Health Sciences Center, Oklahoma City, Oklahoma, USA

Correspondence to Dr Cristina Arriens; cristinaarriens@omrf.org

\begin{abstract}
Objective Although SLE disproportionately affects minority racial groups, they are significantly under-represented in clinical trials in the USA. This may lead to misleading conclusions in race-based subgroup analyses. We conducted focus groups to evaluate the perceptions of diverse patients with lupus about clinical trial participation. Methods A qualitative research design employed three 90 min focus groups led by a trained moderator and guided by the Theory of Planned Behaviour. Open-ended questions about trial participation included advantages and disadvantages (behavioural beliefs), approving and disapproving significant others (normative beliefs), and participation enhancers and barriers (control beliefs). Discussions were recorded, transcribed and analysed to identify emerging themes.
\end{abstract}

Results Patients with SLE ( $n=23$ ) aged 21-72, with increased proportion of minority groups $(65 \%)$, participated. Reported advantages of trial participation included altruism and personal benefit. Disadvantages included uncertainties, disappointment, information burden, and life-health balance. Although some patients had discussed research participation with approving or disapproving family or friends, self-approval superseded external approval. Barriers included logistics and time, and facilitators included flexibility in scheduling, advance notice of studies, streamlined forms, and hope for SLE improvement.

Conclusions Knowledge about potential benefits of clinical trial participation was high. Minority patients demonstrated confidence in making their own informed decisions, but major barriers for all participants included burdensome forms, travel, childcare, and work. These suggest a major impact on minority and all recruitment from behavioural and control aspects, which should be considered in the logistics of trial design. This does not minimise the potential importance of improved access and education about clinical research.

\section{INTRODUCTION}

SLE is a classic autoimmune disease characterised by immune dysregulation, including production of autoantibodies, complement consumption, and production of inflammatory mediators. SLE occurs more frequently in people of African, Hispanic/Latino, and Native American descent than Europeans, ${ }^{12}$ and is generally more active and severe in these groups, including a higher likelihood of developing severe organ involvement, especially lupus nephritis. ${ }^{3-6}$ Despite the increased disease burden in minority groups, their participation in SLE clinical trials has been low in the USA. ${ }^{7}$ Non-white patients comprise roughly two-thirds of SLE prevalent cases, but under half of randomised clinical trial enrollees. ${ }^{8}$ This led to conflicting results about the efficacy in African-American patients based on underpowered subgroup analyses of some trials of belimumab, ${ }^{9} 10$ prompting a study of 448 self-identified black patients. ${ }^{11} 12$

Low rates of minority participation have also been reported in cancer clinical trials. Focus groups and surveys conducted with under-represented groups of patients with cancer found lack of awareness of studies, time commitment, concerns for safety, fear of placebo, fear of loss of confidentiality, transportation concerns, lack of trust, and past experiences to be barriers to participation. ${ }^{13-16}$

A systematic review of minority patients' perceptions of rheumatic disease research participation found trust, understanding racial heterogeneity, and acknowledgement of unconscious bias, among others, to be important. ${ }^{17}$ A clinical trial visit simulation study of individual patients with lupus (6 African-Americans and 12 white) found African-American patients were more likely to express desire for transportation, childcare, and community engagement, while all participants desired shorter consent forms, scheduling flexibility, and feedback 


\section{Patients Contacted $(n=69)$}

\section{Telephone Message Left and Call Not Returned $(n=15)$}

Reasons For Not
Participating $(n=31)$ :
Not Interested $(n=5)$
Transportation $(n=1)$
Not Available $(n=11)$
Work $(n=4)$
Family $(n=7)$
School $(n=3)$

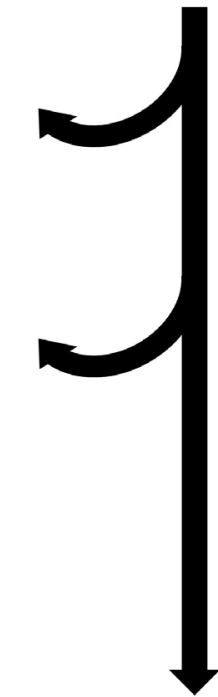

\section{Patients Completing Focus Groups $(n=23)$}

Figure 1 Patient recruitment flow chart. Patients were contacted to determine their interest in participation in the focus groups. A message was left for those who did not answer the phone; however, 15 did not return the calls. Others were unable to participate and gave various reasons, including 11 who had other plans on the dates chosen for the focus groups.

of individual results. ${ }^{18}$ Low rates of clinical trial participation by minority patients with a serious chronic disease such as SLE may significantly increase already profound healthcare disparities by failing to determine whether advanced treatments are appropriate for them. In at least one lupus nephritis study, race appeared to affect treatment response, noting that more patients of African ancestry (12\% of study participants) respond to mycophenolate than cyclophosphamide. ${ }^{19}{ }^{20}$ A study to understand perceptions, incentives, and barriers to clinical trial participation experienced by under-represented groups of patients with lupus is timely. Therefore, using a qualitative design and guided by the Theory of Planned Behaviour, ${ }^{21}$ we conducted focus groups of a diverse lupus population in Oklahoma, with increased proportion of minority patients, to address these questions.

\section{PATIENTS AND METHODS}

\section{Theory of Planned Behaviour}

The Theory of Planned Behaviour is an analytical tool that allows for the incorporation of behavioural change and how its key proximal determinants-attitude, subjective norms, and perceived behavioural control-are linked to a person's intention to engage in the behaviour. Attitude can be described as the individual's evaluation, either favourable or unfavourable, towards performing the behaviour. Subjective norm relates to the normative beliefs or social influences that affect the intention to perform the behaviour. Finally, the perceived behavioural control represents the degree to which an individual considers themselves able to engage in the behaviour. These control beliefs are determined by both situational and internal factors that might make performing the behaviour easy or difficult. ${ }^{21}$ The Theory of Planned Behaviour has been used to evaluate the factors affecting decisions to obtain elective mammography in Native American women in Oklahoma ${ }^{22}$ and the perspectives of young Latina women about contraceptive use.$^{23}$ These are pivotal, health-action decision points with some congruence to that of participating in a clinical trial.

\section{Design and recruitment}

To elicit responses regarding perceptions, incentives and barriers to clinical trial participation in patients with lupus, an exploratory, qualitative design employing focus groups was used. Inclusion criteria included patients who were $\geq 18$ years old and met the SLE classification criteria of the American College of Rheumatology, Systemic Lupus International Collaborating Clinics, or both. ${ }^{24} 25$ Patients with SLE who had participated in the Oklahoma Medical Research Foundation (OMRF) observational cohort and were known not to have transportation impediments were the initial source of patients for this study. Using convenience sampling, 69 potential patients were selected. Patients who were clinical trial-naïve, had only participated in a screening visit, and those who were randomised in a clinical trial were included. Patients were contacted by phone or during in-person clinical encounters to determine their interest in participating in a focus group. Patients self-identifying as African-American, Hispanic/Latino, Native American, or European American (control comparator group) were included, with a focus on ensuring representation by minority patients. Figure 1 provides an overview of the study sample recruitment.

\section{Procedure}

The moderator guide was designed using constructs from the Theory of Planned Behaviour ${ }^{21}$ and contained questions assessing attitudes of patients with SLE towards clinical trial participation, their subjective norms and perceived behavioural control (box 1) The guide was reviewed by the members of the research team and approved by the Institutional Review Board. Three focus groups were conducted, using a semistructured approach, between January and February 2018. The focus groups were held in private meeting facilities within OMRF. Light refreshments were offered to participants. Two trained individuals served as moderator and notetaker. Focus groups were held until thematic saturation was reached with an average of seven participants in each session. Focus groups were audio-recorded and transcribed verbatim prior to data analyses by a professional transcription service (Datalyst). Patient demographics and disease characteristics were obtained from patient charts. 


\section{Box 1 Moderator guide}

1. What do you think about when you think of clinical trials?

2. What do you think are some of the advantages of participating in clinical trials?

3. What do you think are some of the disadvantages of participating in clinical trials?

4. Are there any other advantages and disadvantages associated with participating in clinical trials?

5. Are there any individuals or groups who would like the idea of your participation in clinical trials?

6. Are there any individuals or groups who would not like the idea of your participation in clinical trials?

7. What factors make it easier to participate in a clinical trial?

8. What factors make it more difficult to participate in a clinical trial?

9. Are there any other factors you think would make it easier or more difficult to participate in a clinical trial?

The moderator and the note-taker briefly discussed the emerging themes following each focus group. Two of the researchers reviewed and analysed the session notes and the content of the transcript to identify the themes related to behavioural, normative and control beliefs regarding clinical trial participation. Using topic coding, recurring themes and phrases were identified and labelled into codes. These codes were then collapsed to form larger categories through the process of analytical coding. Subthemes and themes were then created from the identified codes and categories. Then, select remarks from patients were aligned with the corresponding subthemes and themes. Transcripts were rereviewed by the researchers to reach a consensus when discrepancies occurred. Initial inter-rater reliability was high (93\%), and the discrepancies (7\%) were resolved through discussion. Qualitative data analysis was supported through the use of Dedoose. ${ }^{26}$

\section{RESULTS}

\section{Description of participants}

The focus groups included 20 women (6 African-Americans, 5 Hispanics/Latinas, 3 Native Americans, and 6 European Americans) and 3 men (1 African-American and 2 European Americans). Their age ranged from 21 to 72 years, with SLE disease duration ranging from 2 to 26 years. Additionally, they represented a variety of marital status, types of employment, incomes, education levels and healthcare payer groups. Table 1 contains a summary of patient demographics.

\section{Themes}

Three types of beliefs (behavioural, normative, and control) derived from the Theory of Planned Behaviour comprised the main categories for responses. Themes and subthemes are listed in table 2 and summarised in the following sections with sample quotes from patients.
Table 1 Participant characteristics $(n=23)$

\begin{tabular}{|c|c|}
\hline Female, n (\%) & $20(87.0)$ \\
\hline \multicolumn{2}{|l|}{ Race/ethnicity, n (\%) } \\
\hline European American/white & $8(34.8)$ \\
\hline African-American/black & $7(30.4)$ \\
\hline Hispanic/Latino & $5(21.7)$ \\
\hline Native American & $3(13.0)$ \\
\hline Age, median (IQR) & $48.0(41.5-57.5)$ \\
\hline Duration of SLE in years, median (IQR) & $11.1(7.9-16.8)$ \\
\hline \multicolumn{2}{|l|}{ Healthcare payer, n (\%) } \\
\hline Government (eg, Medicare) & $11(47.8)$ \\
\hline Private insurance & $10(43.5)$ \\
\hline Self-pay & $2(8.7)$ \\
\hline \multicolumn{2}{|l|}{ Employment status, n (\%) } \\
\hline Full time & $8(34.8)$ \\
\hline Disabled & $6(26.1)$ \\
\hline Unemployed & $6(26.1)$ \\
\hline Retired & $3(13.0)$ \\
\hline \multicolumn{2}{|l|}{ Marital status, n (\%) } \\
\hline Married & $10(43.5)$ \\
\hline Single & $7(30.4)$ \\
\hline Separated & $3(13.0)$ \\
\hline Divorced & $2(8.7)$ \\
\hline Widowed & $1(4.3)$ \\
\hline \multicolumn{2}{|l|}{ Education (highest), n (\%) } \\
\hline High school & $5(21.7)$ \\
\hline Some college & $16(69.6)$ \\
\hline College, graduate/professional & $2(8.7)$ \\
\hline Annual income (per thousand), median (IQR) & $\$ 17.6(\$ 11.3-\$ 42.5)$ \\
\hline $\begin{array}{l}\text { Distance from clinic in kilometers, median } \\
\text { (IQR) }\end{array}$ & $17.2(11.3-28.3)$ \\
\hline \multicolumn{2}{|l|}{ Geographical residence, n (\%) } \\
\hline Urban & $11(47.8)$ \\
\hline Suburban & $8(34.8)$ \\
\hline Rural & $4(17.4)$ \\
\hline \multicolumn{2}{|l|}{ Clinical trial participation, $\mathrm{n}(\%)$} \\
\hline Experienced & $15(65.2)$ \\
\hline Naïve & $8(34.8)$ \\
\hline
\end{tabular}

Behavioural beliefs

To elicit these beliefs, participants were asked about their perceptions regarding the advantages and disadvantages of participating in clinical trials. The first major theme identified as an advantage was altruism, with subthemes of new drug discovery, including understanding the effects of medications on different patients and improved understanding of SLE for the benefit of future generations.

To me it's research, and I don't expect it to affect my generation at all. I expect it to affect the next generation, because there are so many steps to go 
Table 2 Major themes and subthemes

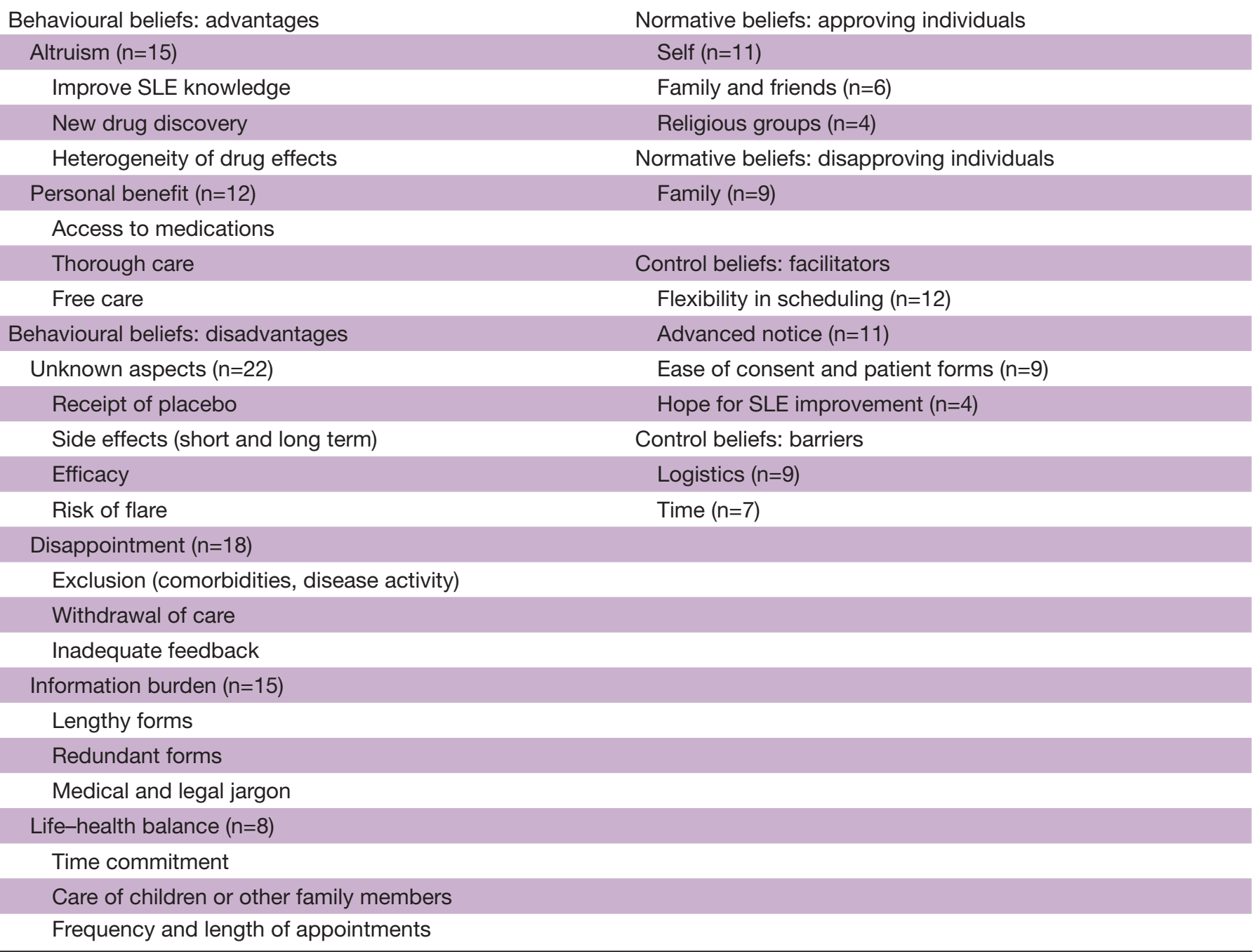

through the studies. (European American man, clinical trial-naïve)

Lupus is very complex - not many people understand it. So through clinical trials, we can even get a better understanding of the disease itself. (AfricanAmerican woman, clinical trial-naïve)

...but I also think it gives them a variety of everybody. You know because everybody's different. All the symptoms are different. And everything, so I think that when you do that, you're just not helping yourself, you're kind of helping everybody. (European American woman, clinical trial-experienced)

Personal benefit was also expressed as an advantage. The participants noted that clinical trials could provide a treatment option for medication that would otherwise be unavailable-whether due to not being approved by the Food and Drug Administration (FDA), not approved for the indication of SLE or not affordable. Patients also noted that they felt they were receiving very good care during studies with frequent provider contact, extra testing, and expenses covered through the study.
I think one of the advantages to having the medication that people don't necessarily have access to because it's so expensive. Most people can't afford to, you know, $\$ 3000$ every time they need medication, so I think that's an advantage. (European American woman, clinical trial-experienced)

Because we do get really good care if we're participating in a study.... (European American woman, clinical trial-experienced)

Patients were equally proactive in discussing the disadvantages of clinical trial participation. Participants were particularly concerned about the unknown aspects of clinical trial participation, especially the outcome and side effects experienced. For newer therapies, concerns for unknown side effects, short term and long term, were seen as a disadvantage to participation.

I was in a couple where you had a 50-50 chance of receiving the actual medication or placebo, and that's hard especially if you're in a 6 month or 
12 month study. (European American woman, clinical trial-experienced)

...something that might cause a flare with a possible drug that you're given and sometimes it can be a scary situation because it causes a flare-up. (Native American woman, clinical trial-naïve)

They do come with a risk. Some of them are very high risk, even to the point of death.... (African-American woman, clinical trial-naïve)

They don't know the results of long term use...finding out 10-20 years down the road that, oh well yeah it took care of this but it caused that. (European American woman, clinical trial-experienced)

Disappointment at different stages of clinical trial participation was noted. Ineligibility due to comorbid conditions, disease activity or results of screening tests was dissatisfying. Those enrolled in studies felt let-down when an effective therapy was stopped due to study completion, the study prematurely halted, or the medication failed to get FDA approval. Patients expressed a desire to receive more information about the outcome of studies. They would like to know much sooner whether they were receiving active drug or placebo, and whether the medication was effective overall.

...when my doctor tried to get me on a trial, she's like well you're not sick enough. (European American woman, clinical trial-experienced)

I think about all the extra medical testing you have to go through. And you may or may not pass, and it's kind of disappointing when you don't. (European American woman, clinical trial-experienced)

I was on one clinical trial when I knew I was getting the drug, and it was helping me...they stopped it...it didn't help that many people. But it did help me. So, what about me? (European American woman, clinical trial-experienced)

...I felt like it helped me a lot, but after the study, I never heard anything back. If I was getting what I was supposed to be getting. (African-American woman, clinical trial-experienced)

Participants also expressed dislike for paperwork related to studies. Consent forms were discussed at length with the assessment that they are too long and redundant. Some also felt the consents included medical and legal jargon that made them more difficult to comprehend. Patients had a similar response when discussing other paperwork, such as patient-reported outcome forms.

Oh, I am just going to repeat that repetitious thing with filling out the paperwork. It is too lengthy, and it is like they have already asked you the same questions over and over and over.... (African-American woman, clinical trial-experienced)

The paperwork that we sign off on that when we agree to participate, it's a lot. (Hispanic/Latina woman, clinical trial-naïve)
The consent forms sometimes can be so long, especially if you have to sign every single paper...you are just not feeling well that day, and your whole body hurts... (Hispanic/Latina woman, clinical trial-naïve)

Finally, the impact of clinical trials on life responsibilities was expressed. Struggles with caretaking of children and other family members often posed issues. Time away from work and school was an additional concern. Compared with normal clinic follow-up, the frequency and length of appointments were considered a disadvantage. Extra testing involved with studies was mentioned, including extra blood drawn and the need to complete some tests at off-site locations.

Something that was kind of frustrating for me was so many appointments so often, and we are trying to you know, make your life normal, with work and kids. (Hispanic/Latina woman, clinical trial-experienced)

It's kind of hard to come in and...take off of work once a month. (African-American man, clinical trial-experienced)

You've got to take away from the family [and] find someone to watch the kiddos. (Hispanic/Latina woman, clinical trial-naïve)

\section{Normative beliefs}

These beliefs involve individuals who influence them to engage or not engage in a certain behaviour. Although some patients discussed research participation with family, friends, or religious groups, self-determination superseded external influence.

My family and friends are really supportive. They think it is wonderful that I am in a study that I would choose to do that. I've been to other doctors, and I am very thankful to be a part of this study. Regardless of what the outcome is. To me it is a blessing to be in it. My family agrees with all that. (European American woman, clinical trial-experienced)

And so I do not really have anyone to say, well you think you ought to do this, or you think, it is going to work? I make my own decision. (African-American man, clinical trial-experienced)

My church has been real positive and prayer groups and praying for me and the studies. (Hispanic/Latina woman, clinical trial-experienced)

My family is supportive yet apprehensive at the same time. (European American woman, clinical trial-experienced)

[My mom] would be so like - you know you have a family. You have kids. She would be supportive, but she would be the one that would be like think about it. My husband would be my listener, but I always do me...I still pull what I want to pull in the end, whether I want to do it or not. And I listen to both ends of it. (Hispanic/Latina woman, clinical trial-naïve) 


\section{Control beliefs}

According to the Theory of Planned Behaviour, there are factors that might make it easier or more difficult to engage in a behaviour. Accordingly, participants identified enabling and barrier factors when asked to share them. Facilitators included flexibility in scheduling that could incorporate evenings, weekends or locations much closer to their homes. Some also expressed the need to have study visits combined with their regular office visits. Advance notice to aid in making arrangements for childcare or work was also noted.

So as long as they are up front, you know, with your obligations. If you are interested in this study, this is what it is going to require, you know, two hours clinic visit once a week or once every twoweeks or whatever. (European American woman, clinical trial-experienced)

Removing redundancy in paperwork, shortening the length of paperwork, an option for the use of electronic technology for forms and the option for receiving documents electronically prior to the day of visits were elicited as enabling factors.

The paperwork. If they would just like get it maybe digitalized where you could just do like a stamp and sign it one time.... (Hispanic/Latina woman, clinical trial-experienced)

...reduce the redundancy...I think that is the whole reason behind digital is it is quicker, and it is easier and faster. (African-American woman, clinical trial-naïve)

Finally, knowing that they are contributing to SLE improvement for themselves, other patients and future generations also motivated participation. As a result, participants desired prompt poststudy feedback along with results of biomarker studies in order to reinforce their contribution to the advancement of disease knowledge.

The hope of getting well and finding a cure. (European American woman, clinical trial-experienced)

It would be good or beneficial, I guess, to know that with your participation does make a difference.

(Native American woman, clinical trial-naïve)

In addition to the enabling factors, participants identified barriers to clinical trial participation, including logistics and time. Travel cost as well as issues surrounding finances such as lost wages were noted. Time as the barrier was expressed as travel, length, and frequency of appointments, as well as the time it took to get tests done outside of the clinic.

I really think that time constraint is - I mean that's my reasoning why I've chosen not to participate in some of them. It's just because of time. (Hispanic/Latina woman, clinical trial-naïve)
Not only did I have that day here at the office getting all the things I needed done here, but then I had to make appointments at other places. (European American woman, clinical trial-experienced)

While side effects from clinical trials were mentioned by a couple of patients in the initial session, other members of the group did not corroborate this. When this question was posed to participants of the remaining two focus groups during the process of iteration, they agreed it was not a factor they considered. Another barrier expressed was the use of jargon and confusing words in the consent forms. However, according to patients, one-on-one consultation with doctors and other research personnel ameliorated this disadvantage.

\section{DISCUSSION}

This focus group study included a diverse group of patients with SLE, with increased proportion of minority patients, to examine attitudes, beliefs, barriers, and facilitators to clinical trial participation. The inclusion of African-American and Native American patients, as well as Hispanic/Latino patients, was a strength of the study. Weaknesses included the exclusion of patients known to have transportation impediments, since this may be an important barrier to clinical trial participation. Additionally, we included both city dwellers and patients from distant rural communities. The age ranged from 21 to 72

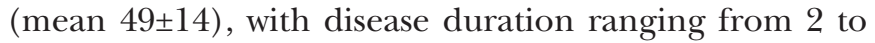
26 years. Recent studies of SLE prevalence have noted the average age of female and male patients to be $43 \pm 16$ and $41 \pm 17$ years, with adult patients ranging from 18 to $\geq 80$ years. $^{27-30}$ Older patients were over-represented in our study, which likely explains the longer disease duration in the group. Also, our patient population may not be representative of a more geographically dispersed population, especially since we included a number with experience in clinical trials. Familiarity with clinical research may, however, have provided an advantage, in that participants were able to identify dissatisfaction with many aspects of the recruitment and screening process, especially when they had gone through this extensive process and did not qualify for participation in studies.

The focus groups were conducted in an iterative process, where questions and probes were modified in subsequent groups to test earlier findings and disconfirm anomalous ones. By the end of the third focus group, saturation had been reached, and no new phenomena were being generated. The Theory of Planned Behaviour guided the evaluation of behavioural, normative, and control beliefs and revealed key themes. Although some insights might not be actionable, others illuminated opportunities to facilitate clinical trial participation. When asked about the advantages of participating in clinical trials, the patients agreed that it was necessary for new drug discovery, improving research, and providing answers to the unknown questions regarding lupus. Some patients expressed that participating in clinical trials 
provided access to otherwise expensive drugs. This is not surprising given that the annual direct medical cost of SLE has been estimated to be high when compared with other rheumatic conditions, with treatment being the main cost driver. ${ }^{31}{ }^{32}$ As a result, healthcare payer status may influence decisions to participate in clinical trials. Also patients noted the increased medical attention and surveillance obtained with trial participation, and the prompt responses from the study team.

Disadvantages included discontinuation/withdrawal, too many appointments, anxiety about the outcome, worsening symptoms, and frustration about not knowing how much benefit one could expect. Although the term 'guinea pig' was brought up in the discussion, it was in a joking manner to demonstrate unknown concerns with therapies regarding efficacy and side effects. Patients expressed that lack of feedback about the outcome of the clinical trials is a disadvantage. Our patients did not express significant distrust, despite prior research noting issues with the distrust of clinical research and medical researchers. ${ }^{13-16}$ This is important considering that historically, non-participation of minorities in medical research, especially in the African-American community, has been linked to a history of abuse, with the Tuskegee Syphilis Study serving as a persuasive cautionary precedent. ${ }^{33-35}$ A recent review noted distrust of medical providers was not a limiting factor for minority participation in clinical trials. ${ }^{36}$ Our focus groups each included a mix of races and ethnicities; however, it is possible that more concordant groups would be more likely to share ideas of distrust. Similar to feedback obtained from other trials conducted in oncology, concerns regarding receipt of placebo, safety, efficacy, time burden, and additional clinic visits were found in our groups. ${ }^{13-16}$

On eliciting subjective norms, some patients reported that most family members were supportive, but their opinions were not seen as critical and would not weigh much regarding whether to enrol in trials. Most responded that they, as patients with lupus, were the only ones responsible for making such decisions. Unlike prior reports suggesting that the opinions of referent ones can have an impact on engaging in certain behaviours, ${ }^{23}{ }^{37}$ this was not cited as a decisive factor here. Our participants did express the experience that the public misunderstands lupus, leading to patients feeling isolated and sometimes unsupported. These sentiments were similar to another study conducted in patients with lupus, ${ }^{38}$ and might provide one explanation for the weaker impact of opinions of referent ones.

SLE most commonly occurs in women of childbearing age, a younger population than found in many cancer populations. Therefore, it is not surprising that issues of childcare and time away from work or school were key barriers to study participation in our groups, and advanced notice, scheduling flexibility and streamlined paperwork were noted facilitators.

Although there is limited information regarding barriers to trial participation for patients with SLE, DasMahapatra et $a l^{99}$ surveyed patients with multiple medical conditions $(\mathrm{n}=1621)$. Only $53(3 \%)$ were self-reported patients with SLE, and data specific to SLE were not reported. Data from all patients who were invited to participate in a trial and declined suggested similar barriers to those we report in the current study, the majority of those surveyed were also interested in learning more about trials $(n=1434,88 \%)$. Facilitating factors included hope for health improvement, the reputation of the institution and coverage of medical bills in case of trial-related injury. ${ }^{39}$

Responses from our minority participants were similar to participants of European descent. However, gender differences in facilitators and barriers were revealed. Female participants emphasised the importance of having convenient and flexible scheduling times for clinical trials, as well as provisions for childcare. This suggests that practical approaches to addressing barriers of time, childcare, and travel might have a significant impact on participation of patients with lupus in clinical trials.

In conclusion, this qualitative study was undertaken to better understand the perspective of patients with SLE on clinical trial participation. Our groups were enriched for minority patients, who have been under-represented in SLE clinical trials despite their higher disease burden. We were interested in observing whether minority patients had unique problems with trial participation, but despite proactive participation by all there was very little difference in the factors facilitating and preventing trial participation based on race or ethnicity. Our participants understood the importance of clinical research, and the hope for improved outcomes for future generations was prevalent. Since many of our participants had experience in clinical trials, this could have influenced their perception of research studies. The insights that participants provided towards approaches to improve trial participation were primarily practical, including streamlining paperwork and study visits to reduce time commitment, assistance with travel and childcare, and providing prompt feedback. Trial design and implementation can incorporate such solutions and might improve participation of minority patients with SLE and all patients.

Acknowledgements We would like to thank the patients who gave their time and expressed their opinions during our focus groups. We would also like to thank Paul Kamp and D'Angelo Grant for their assistance with recruitment of participants.

Contributors All authors were involved in drafting the article or revising it critically for important intellectual content, and approved the final version for publication. CA and MO had full access to all of the data in the study and take responsibility for the integrity of the data and the accuracy of data analysis. Study concept and design: JTM, CA and MO. Acquisition of data: CA, TA, AT, EC, SK, FC, JAJ, JTM and MO. Analysis and interpretation of data: CA and MO.

Funding This project was supported by the US Department of Health and Human Services: Office of Minority Health CPI-MP-17-002-1 2017 National Lupus Outreach and Clinical Trial Education Program.

Disclaimer The authors have used the terminology of African-American to describe patients of African origin in our study per standard terminology for our region. When referencing other studies, terminology used by the original authors has been used.

Competing interests CA: AstraZeneca, BMS, GSK. JAJ: Progentec, Xencor, AbbVie, Janssen. JTM: BMS, GSK, UCB, Questcor, EMD Serono, Amgen, Celgene, 
Pfizer, RemeGen, Exagen, Medlmmune, Lilly, Janssen, Xencor, Sanofi, Neovacs, Immupharma, Astellas, Glenmark.

Patient consent for publication Not required.

Ethics approval The Institutional Review Board at the Oklahoma Medical Research Foundation approved the study, and focus group participants provided written informed consent.

Provenance and peer review Not commissioned; externally peer reviewed. Data availability statement Data are available upon reasonable request.

Open access This is an open access article distributed in accordance with the Creative Commons Attribution Non Commercial (CC BY-NC 4.0) license, which permits others to distribute, remix, adapt, build upon this work non-commercially, and license their derivative works on different terms, provided the original work is properly cited, appropriate credit is given, any changes made indicated, and the use is non-commercial. See: http://creativecommons.org/licenses/by-nc/4.0/.

\section{ORCID iDs}

Cristina Arriens http://orcid.org/0000-0002-9546-1664

Aikaterini Thanou http://orcid.org/0000-0002-1161-7618

Motolani E Ogunsanya http://orcid.org/0000-0002-4005-0446

\section{REFERENCES}

1 Alarcón GS, Rodríguez JL, Benavides G, et al. Systemic lupus erythematosus in three ethnic groups. V. Acculturation, healthrelated attitudes and behaviors, and disease activity in Hispanic patients from the LUMINA cohort. LUMINA Study Group. lupus in minority populations, nature versus nurture. Arthritis Care Res 1999;12:267-76.

2 Ferucci ED, Johnston JM, Gaddy JR, et al. Prevalence and incidence of systemic lupus erythematosus in a population-based registry of American Indian and Alaska native people, 2007-2009. Arthritis Rheumatol 2014;66:2494-502.

3 Richman IB, Taylor KE, Chung SA, et al. European genetic ancestry is associated with a decreased risk of lupus nephritis. Arthritis Rheum 2012;64:3374-82.

4 Bastian HM, Roseman JM, Mcgwin G, et al. Systemic lupus erythematosus in three ethnic groups. XII. risk factors for lupus nephritis after diagnosis. Lupus 2002;11:152-60.

5 Seligman VA, Lum RF, Olson JL, et al. Demographic differences in the development of lupus nephritis: a retrospective analysis. $A m ~ J$ Med 2002;112:726-9.

6 Arriens C, Chen S, Karp DR, et al. Prognostic significance of repeat biopsy in lupus nephritis: histopathologic worsening and a short time between biopsies is associated with significantly increased risk for end stage renal disease and death. Clinical Immunology 2017;185:3-9.

7 Sheikh SZ, Wanty NI, Stephens J, et al. The state of lupus clinical trials: minority participation needed. JCM 2019;8:1245.

8 Falasinnu T, Chaichian Y, Bass MB, et al. The representation of gender and Race/Ethnic groups in randomized clinical trials of individuals with systemic lupus erythematosus. Curr Rheumatol Rep 2018;20:20

9 Furie R, Petri M, Zamani O, et al. A phase III, randomized, placebocontrolled study of belimumab, a monoclonal antibody that inhibits B lymphocyte stimulator, in patients with systemic lupus erythematosus. Arthritis Rheum 2011;63:3918-30.

10 Wallace DJ, Stohl W, Furie RA, et al. A phase II, randomized, doubleblind, placebo-controlled, dose-ranging study of belimumab in patients with active systemic lupus erythematosus. Arthritis Rheum 2009;61:1168-78.

11 D'Cruz DP, Maksimowicz-McKinnon K, Oates JC, et al. Efficacy and safety of belimumab in patients of black race with systemic lupus erythematosus: results from the embrace study. Lupus Sci Med 2019;6:A149-50.

12 Guedes-Barboza LS, Saxena A, Ginzler E, et al. Efficacy of belimumab in patients of black race with systemic lupus erythematosus and high disease activity or renal manifestations. Arthritis Rheumatol 2019;71.

13 Bruner DW, Jones M, Buchanan D, et al. Reducing cancer disparities for minorities: a multidisciplinary research agenda to improve patient access to health systems, clinical trials, and effective cancer therapy. JCO 2006;24:2209-15.

14 Fouad MN, Partridge E, Green BL, et al. Minority recruitment in clinical trials: a conference at tuskegee, researchers and the community. Ann Epidemiol 2000;10:S35-40.
15 Erves JC, Mayo-Gamble TL, Malin-Fair A, et al. Needs, priorities, and recommendations for engaging underrepresented populations in clinical research: a community perspective. J Community Health 2017;42:472-80.

16 Schmotzer GL. Barriers and facilitators to participation of minorities in clinical trials. Ethn Dis 2012;22:226-30.

17 Lima K, Phillip CR, Williams J, et al. Factors associated with participation in rheumatic Disease-Related research among underrepresented populations: a qualitative systematic review. Arthritis Care Res 2019. doi:10.1002/acr.24036. [Epub ahead of print: 26 Jul 2019].

18 Lim SS, Kivitz AJ, McKinnell D, et al. Simulating clinical trial visits yields patient insights into study design and recruitment. Patient Prefer Adherence 2017;11:1295-307.

19 Isenberg D, Appel GB, Contreras G, et al. Influence of race/ ethnicity on response to lupus nephritis treatment: the ALMS study. Rheumatology 2010;49:128-40.

20 Appel GB, Contreras G, Dooley MA, et al. Mycophenolate mofetil versus cyclophosphamide for induction treatment of lupus nephritis. J Am Soc Nephrol 2009;20:1103-12.

21 Ajzen I. The theory of planned behavior. Organ Behav Hum Decis Process 1991;50:179-211.

22 Tolma EL, Stoner JA, Li J, et al. Predictors of regular mammography use among American Indian women in Oklahoma: a cross-sectional study. BMC Womens Health 2014;14:101.

23 Carvajal DN, Gioia D, Mudafort ER, et al. How can primary care physicians best support contraceptive decision making? A qualitative study exploring the perspectives of Baltimore Latinas. Women's Health Issues 2017;27:158-66.

24 Hochberg MC. Updating the American College of rheumatology revised criteria for the classification of systemic lupus erythematosus. Arthritis Rheum 1997;40:1725.

25 Petri M, Orbai A-M, Alarcón GS, et al. Derivation and validation of the systemic lupus international collaborating clinics classification criteria for systemic lupus erythematosus. Arthritis Rheum 2012;64:2677-86.

26 Dedoose Version. 6.1.18. web application for managing, analyzing, and presenting qualitative and mixed method research data. Los Angeles, CA: SocioCultural Research Consultants, LLC, 2015. www. dedoose.com

27 Lim SS, Bayakly AR, Helmick CG, et al. The incidence and prevalence of systemic lupus erythematosus, 2002-2004: the Georgia lupus registry. Arthritis Rheumatol 2014;66:357-68.

28 Somers EC, Marder W, Cagnoli P, et al. Population-Based incidence and prevalence of systemic lupus erythematosus: the Michigan lupus epidemiology and surveillance program. Arthritis Rheumatol 2014;66:369-78.

29 Dall'Era M, Cisternas MG, Snipes K, et al. The incidence and prevalence of systemic lupus erythematosus in San Francisco County, California: the California lupus surveillance project. Arthritis Rheumatol 2017;69:1996-2005.

30 Izmirly PM, Wan I, Sahl S, et al. The incidence and prevalence of systemic lupus erythematosus in New York County (Manhattan), New York: the Manhattan lupus surveillance program. Arthritis Rheumatol 2017;69:2006-17.

31 Doria A, Amoura Z, Cervera R, et al. Annual direct medical cost of active systemic lupus erythematosus in five European countries. Ann Rheum Dis 2014;73:154-60.

32 Li T, Carls GS, Panopalis P, et al. Long-Term medical costs and resource utilization in systemic lupus erythematosus and lupus nephritis: a five-year analysis of a large Medicaid population. Arthritis Rheum 2009;61:755-63.

33 Corbie-Smith G, Thomas SB, Distrust SGDM. Race, and research. Arch Intern Med 2002;162:2458-63.

34 Corbie-Smith G, Thomas SB, Williams MV, et al. Attitudes and beliefs of African Americans toward participation in medical research. J Gen Intern Med 1999;14:537-46.

35 Brandon DT, Isaac LA, LaVeist TA. The legacy of tuskegee and trust in medical care: is tuskegee responsible for race differences in mistrust of medical care? J Natl Med Assoc 2005;97:951-6.

36 Anjorin A, Lipsky P. Engaging African ancestry participants in SLE clinical trials. Lupus Sci Med 2018;5:e000297.

37 Ogunsanya ME, Brown CM, Odedina FT, et al. Beliefs regarding prostate cancer screening among black males aged 18 to 40 years. Am J Mens Health 2017;11:41-53.

38 Ogunsanya ME, Brown CM, Lin D, et al. Understanding the disease burden and unmet needs among patients with cutaneous lupus erythematosus: a qualitative study. Int $J$ Womens Dermatol 2018;4:152-8.

39 DasMahapatra P, Raja P, Gilbert J, et al. Clinical trials from the patient perspective: survey in an online patient community. BMC Health Serv Res 2017;17:166. 